\title{
Dynamic Characteristics of the Herringbone Groove Gas Journal Bearings: Numerical Simulations
}

\author{
Bin Wang, ${ }^{1,2}$ Yongtao Sun, ${ }^{1,2,3,4}$ and Qian Ding ${ }^{1,2}$ \\ ${ }^{1}$ Department of Mechanics, Tianjin University, Tianjin 300072, China \\ ${ }^{2}$ Tianjin Key Laboratory of Nonlinear Dynamics and Control, Tianjin 300072, China \\ ${ }^{3}$ State Key Laboratory for Strength and Vibration of Mechanical Structures, Xian Jiaotong University, Xian 710049, China \\ ${ }^{4}$ State Key Laboratory of Structural Analysis for Industrial Equipment, Dalian University of Technology, Dalian 116024, China
}

Correspondence should be addressed to Qian Ding; qding@tju.edu.cn

Received 4 July 2016; Revised 17 October 2016; Accepted 15 November 2016

Academic Editor: Emiliano Mucchi

Copyright (c) 2016 Bin Wang et al. This is an open access article distributed under the Creative Commons Attribution License, which permits unrestricted use, distribution, and reproduction in any medium, provided the original work is properly cited.

\begin{abstract}
Dynamic characteristics of the herringbone grooved gas journal bearings (HGGJB) under fluid-structure interactions are systematically investigated using the finite element method. Stability and bearing capacity of the HGGJB are estimated and compared with those of the plain gas journal bearings (PGJB). Influences of the structural parameters, including the spiral angle, the groove number, the groove depth, the pressure relief hole diameter, the bearing radial clearance, the length to diameter ratio, and the rotating speed, on dynamic characteristics of HGGJB are analyzed. To verify the numerical simulation results, pressure nephograms and cross-section pressure curves of the same rotor model, calculated by the numerical simulation and the theoretical method, respectively, are compared. Similar results are obtained. Compared to the common constrained boundary conditions in the previous numerical simulations, boundary conditions adopted in this paper are complete self-absorption and the change of the gas inlet and outlet depends on the rotating state of the rotor, which are more accordant with the real dynamic characteristics of the HGGJB. In all, the results presented in this paper provide a deeper and better understanding of the dynamic characteristics of the HGGJB under fluid-structure interactions.
\end{abstract}

\section{Introduction}

As a vital part of the rotor system, the herringbone grooved gas journal bearings (HGGJB) have important applications in high speed, rotating machinery (such as those found in textile machinery, refrigerator, gas recycling system, and so on) due to their attractive stability characteristics. This advantage is very important for journal concentric operation within the bearing annular space since herringbone grooves can inhibit the whirl instability which often occurs in the self-acting journal bearings [1].

To deeply and completely understand the dynamic characteristics of the HGGJB, a lot of research has been done. Zirkelback and San Andrés [1] introduced the finite element analysis for prediction of the static and dynamic responses of a rotor supported by HGGJBs. The optimum dynamic coefficients were determined through analysis of the bearing geometry parametric. Jang and Chang [2] investigated the effects of cavitation on the performance of a herringbone grooved journal bearing of the spindle motor in a computer hard disk drive. The Reynolds equation incorporating Elrod algorithm was transformed to computational space and solved by the finite volume method. Jang and Yoon [3] performed the nonlinear dynamic analysis of a herringbone grooved journal bearing with plain sleeve and a plain journal bearing with herringbone grooved sleeve under static and dynamic load, where FEM is used to solve the Reynolds equation in order to calculate the pressure distribution in a fluid film. Rao and Sawicki [4] analyzed stability characteristics of the herringbone grooved journal bearings taking into account cavitation of the fluid flow. Based on the experimental method, Gad et al. [5] introduced the beveled-step groove profile to obtain the optimum groove geometry for herringbone grooved journal bearings. The group of Cheng-Chi Wang performed bifurcation analysis of an aerodynamic journal bearing system considering the effect of stationary herringbone grooves [6]. 
They also theoretically studied the nonlinear behavior of the flexible rotor supported by HGGJB [7], a relative short HGGJB system [8], and the spherical gas-lubricated bearing system [9], respectively. Hirayama et al. [10] discussed the optimization of groove dimensions in herringbone-grooved journal bearings with the aim of designing precision spindles with improved run-out characteristics. Based on the use of frequency dependent dynamic coefficients and on the rational function approximation of the resulting impedances, Hassini and Arghir proposed a novel simplified method for simulating large nonlinear displacements [11] and stability analysis in gas lubricated bearings $[12,13]$. This method avoids solving the unsteady compressible thin film fluid equations, can be applied to any bearing or seal whose impedance is approximated by rational transfer functions, and is applicable for both rigid and flexible rotors. Schiffmann and Favrat [14] compared the influences of the real gas and the perfect gas on herringbone grooved journal bearings and encouraged bearing designers to carefully consider the real gas effects. Chen et al. [15] analyzed the HGGJB with groove-ridge discontinuity and obtained the distribution of the pressure in the fluid film. Schiffmann [16] found the optimum groove geometry by coupling the gas bearing supported rotor model with a multiobjective optimizer and attempted to set up general design guidelines for enhanced gas-lubricated herringbone grooved journal bearings.

However, most of the above-mentioned researches investigated either the static characteristics and the dynamic coefficients of HGGJB in steady state or the optimization of only one parameter of the HGGJB or a new method for stability analysis of the HGGJB. A systematic study about the influences of all the related parameters on dynamic characteristics of the HGGJB has seldom been done. Therefore, in this paper, through the commercial software Ansys ${ }^{\circledR}$, the dynamic characteristics of the HGGJB under fluid-structure interactions are systematically studied. First, to verify the correctness of the numerical simulations carried out in this paper, the pressure nephograms and the cross-section pressure curves of the same rotor model, calculated by the theoretical method and the numerical simulation, respectively, are compared. Then, to highlight advantages of the HGGJB, the stability and bearing capacity of the HGGJB are compared with those of the plain gas journal bearings (PGJB). Finally, the effects of different parameters, including the spiral angle, the groove number, the groove depth, the pressure relief hole diameter, the bearing radial clearance, and the length to diameter ratio, on dynamic characteristics of the HGGJB are given one by one. At the same time, effect of the bearing capacity on rotor trajectory of the HGGJB is shown.

In the previous numerical simulations on dynamic characteristics of the HGGJB, the boundary conditions are usually constrained. In this paper the boundary conditions of the HGGJB are complete self-absorption and the change of the gas inlet and outlet depends on the rotating state of the rotor, which confirm better to the real dynamic characteristics of the HGGJB.
TABLE 1: Basic parameters of the journal bearing rotor system.

\begin{tabular}{lcc}
\hline $\begin{array}{l}\text { Diameter of the } \\
\text { disk } D /(\mathrm{mm})\end{array}$ & $\begin{array}{c}\text { Axial length/diameter } \\
L_{0} / D_{0} /(\mathrm{mm})\end{array}$ & $\begin{array}{c}\text { Thickness/diameter of } \\
\text { the bearing pedestal } \\
B_{1} / D_{1} /(\mathrm{mm})\end{array}$ \\
\hline 100 & $200 / 50$ & $20 / 50.10$ \\
\hline
\end{tabular}

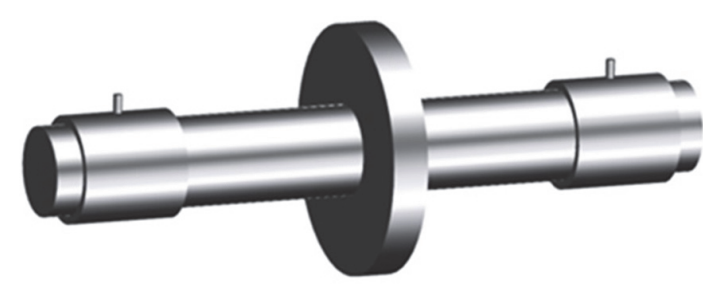

FIGURE 1: The geometry model of the journal bearing rotor structure.

\section{The Geometric Model of the Rotor System and the Finite Element Model}

First, the geometrical model of a rotor system and the finite element model used for analyzing the rotor system under fluid-structure interactions are described. The details of fluidstructure interactions are given in Appendix A.

2.1. The Geometric Model of the Rotor Structure. Figure 1 shows the typical geometry of a journal bearing rotor structure, in which the gas film can be plain type (Figure 2(a)) or herringbone groove type (Figure 2(b)). A compressible gas fills the space between the stationary bearing and the rotating journal. The fixed basic parameters of the rotor system are given in Table 1 . The width $B_{0}$ of the disk varies with the bearing capacity and the length $L_{1}$ of the bearing pedestal varies with the length to width ratio of the bearing. The models given in Figures 1 and 2 are used to analyze the fluid-structure interactions of the rotor bearing system through the FEM.

2.2. The Finite Element Model. Figure 3 depicts the mesh of the journal bearing rotor structure. Local grids of the plain and the herringbone groove gas films are shown in Figures 4(a) and 4(b), respectively. Both the rotor structure and the gas film are divided into hexahedral grids. Compared to the unstructured tetrahedral grid, the hexahedral grid structure has higher calculation accuracy and better quality of grid, especially for the gas film clearance flow problem. It can greatly reduce the number of grids and improve the calculation efficiency at the same precision.

To describe rotor's trajectory, the dynamic grid technology is used. The boundaries are the opening inlet and outlet. The initial position is the centre of the bearing pedestal. In process of the fluid-structure interactions, the bearing gas film deforms due to the load from the rotor (Figures 5 and 6). The grid deformation could reflect the dynamic performance of the rotor system during the calculation process. Dynamic grid technique could completely describe the rule of the rotor-bearing system. 


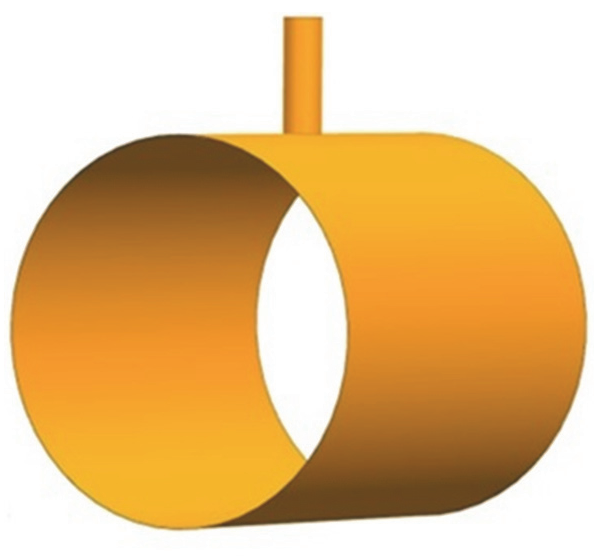

(a)

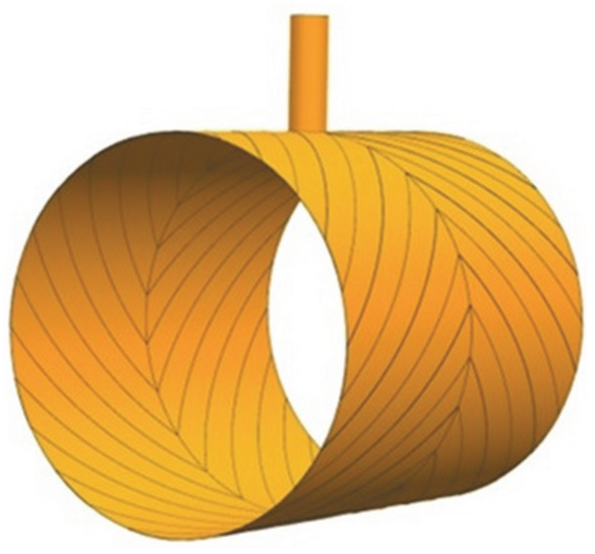

(b)

FIgURE 2: (a) The plain gas film model; (b) the herringbone groove gas film model.

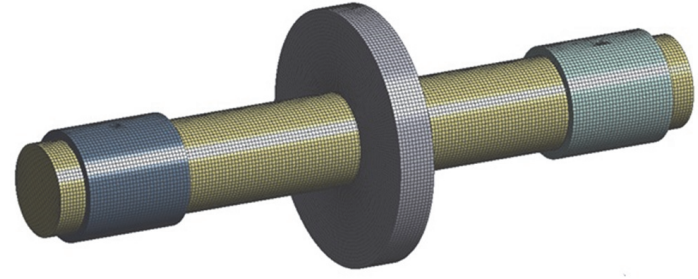

Figure 3: The finite element model of the rotor system.

TABLE 2: The change of the eccentricity with the grid number.

\begin{tabular}{lccccc}
\hline Grid number & 2165428 & 4279624 & 8026475 & 15897792 & 30879884 \\
\hline Eccentricity $(\mu \mathrm{m})$ & 47.31 & 44.28 & 42.56 & 41.60 & 41.59
\end{tabular}

2.3. The Grid Sensitivity Analysis. In order to eliminate the influence of the grid number, the grid sensitivity is analyzed (Table 2). The parameters of the model are the optimized parameters which will be discussed in Section 3. From Table 2 it is easy to see that the eccentricity decreases with the increase of the grid number and it is almost the same when the grid number increases from 15897792 to 30879884 . In order to increase the calculation efficiency, 15897792 is selected for the grid number.

\section{Verification of the Numerical Simulations}

The pressure nephogram reflects the bearing pressure distribution under certain bearing capacity and rotating speed. And the cross-section pressure curves can be more intuitive to reflect the rule of circumferential pressure distribution. To verify the correctness of the numerical simulations carried out in this paper, the pressure nephograms and the crosssection pressure curves of the same rotor model for the HGGJB and PGJB, obtained, respectively, by the theoretical method and the numerical simulation, are compared in this part. The parameters for the HGGJB are the following optimized parameters: groove number 12 , spiral angle number
TABLE 3: Basic parameters of the PGJB.

\begin{tabular}{lcccccc}
\hline$L(\mathrm{~mm})$ & $R(\mathrm{~mm})$ & $C_{0}(\mathrm{~mm})$ & $P_{a}(\mathrm{~Pa})$ & $\mu(\mathrm{Pa} \cdot \mathrm{s})$ & $\omega(\mathrm{r} / \mathrm{min})$ & $\Lambda$ \\
\hline 60 & 25 & 0.05 & 101325 & $1.8 \times 10^{-5}$ & $1.0 \times 10^{4}$ & 1.7 \\
\hline
\end{tabular}

$45^{\circ}$, groove depth $50 \mu \mathrm{m}$, pressure relief hole diameter $3 \mathrm{~mm}$, bearing radial clearance $50 \mu \mathrm{m}$, and length to diameter ratio 1.2. In addition, the recess width ratio is fixed and it is $1: 1$. The rotating speed of the rotor and the bearing capacity are kept at $10000 \mathrm{r} / \mathrm{min}$ and $2 \mathrm{~kg}$. The parameters of the PGJB are given in Table 3 , and the bearing capacity is $0.5 \mathrm{~kg}$.

To theoretically analyze the pressure of the PGJB and the HGGJB, usually the method of the similarity theory is adopted to derive the dimensionless form of the Reynolds equation and then solve the Reynolds equation through the finite difference method in which the Reynolds equation is transferred from the rectangular coordinate system to the oblique coordinate system. The details of the finite difference method are given in Appendix B.

The dimensionless Reynolds equation for the PGJB in the rectangular coordinate system is

$$
\frac{\partial}{\partial \varphi}\left(H^{3} \frac{\partial p}{\partial \varphi}\right)+\left(\frac{D^{2}}{L}\right) \frac{\partial}{\partial \lambda}\left(H^{3} \frac{\partial P}{\partial \lambda}\right)=3 \frac{\partial H}{\partial \varphi}
$$

where $H=1+\varepsilon \cos \varphi\left(\varepsilon=e / C_{0}\right), \lambda=2 z / L$ ( $L$ is the length of the bearing), $H=h / C_{0}\left(C_{0}\right.$ is the clearance of the radius), and $P=\psi^{2} p / 2 \Omega \mu\left(\psi=C_{0} / R\right.$ is the ratio of the clearance).

Through the following coordinate transformation (Figure 7):

$$
\begin{aligned}
& \varphi=x_{1}+y_{1} \sin \beta, \\
& \lambda=y_{1} \cos \beta
\end{aligned}
$$




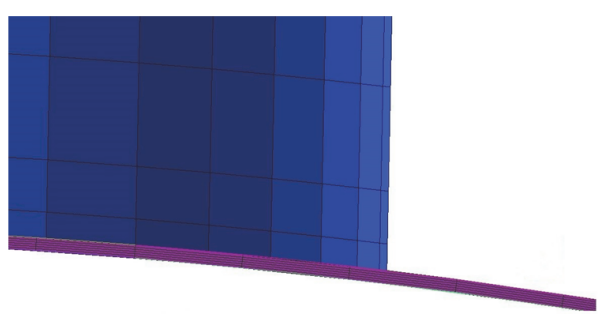

(a)

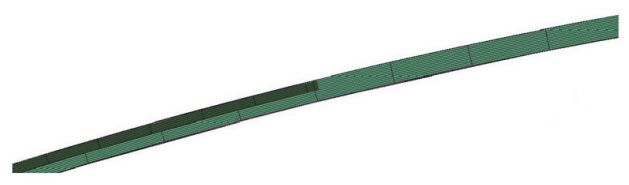

(b)

FIGURE 4: The local grid of (a) the plain gas film and (b) the herringbone groove gas film.

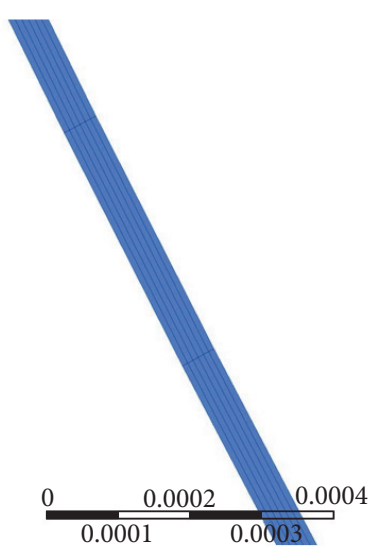

$(\mathrm{m})$

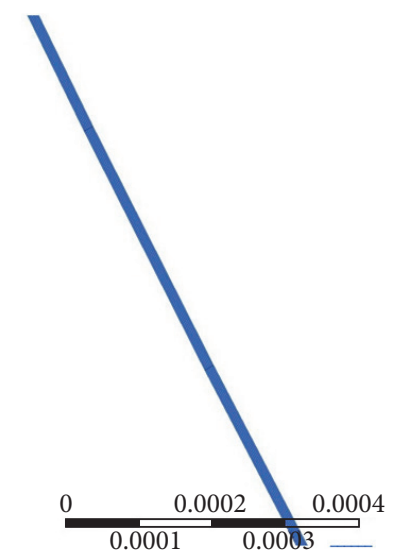

(m)
FIGURE 5: Grid deformation of the plain gas film.

the Reynolds equation is transferred from the rectangular coordinate system (in (1)) to the oblique coordinate system for HGGJB as

$$
\begin{aligned}
& \frac{\partial}{\partial x_{1}}\left(H^{3} \frac{\partial p}{\partial x_{1}}\right)+\left(\frac{D}{L}\right)^{2} \\
& \cdot \frac{1}{\cos \beta}\left\{\frac{\partial}{\partial y_{1}}\left[\frac{H^{3}}{\cos \beta}\left(\frac{\partial p}{\partial y_{1}}-\frac{\partial p}{\partial x_{1}} \sin \beta\right)\right]\right. \\
& \left.-\frac{\partial}{\partial x_{1}}\left[\frac{H^{3}}{\cos \beta}\left(\frac{\partial p}{\partial y_{1}}-\frac{\partial p}{\partial x_{1}} \sin \beta\right)\right] \sin \beta\right\}=3 \frac{\partial H}{\partial x_{1}},
\end{aligned}
$$

in which the gas film thickness $H$ under the oblique coordinate system is

$$
H=1+\varepsilon \cos \left(x_{1}+y_{1} \sin \beta-\theta\right) .
$$

Discretizing the bearing lubrication film and solving the Reynolds Eqs. (1) and (3) through the finite difference method gives the pressure nephogram of the rotor system and the corresponding circumferential pressure distribution curve of the cross-section for the PGJB (Figure 8) and HGGJB (Figure 9), respectively. In the calculation, the environmental,

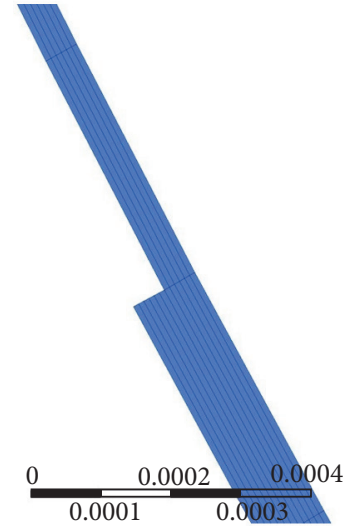

(m)

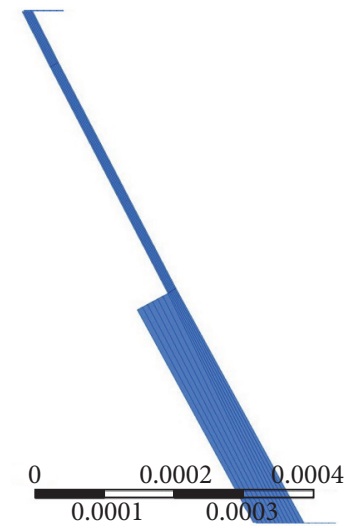

(m)
FIGURE 6: Grid deformation of the herringbone groove gas film.

symmetric, and periodic boundary conditions for the finite difference method are, respectively, as follows:

$$
\begin{aligned}
P\left(\frac{l}{2 r}, \varphi\right) & =1, \\
P(\lambda, \varphi) & =P(-\lambda, \varphi)=1 \mathrm{~atm}, \\
P(\lambda, \varphi) & =P(\lambda, \varphi+2 \pi) .
\end{aligned}
$$

Comparing the pressure nephograms by the theoretical method (Figures 8(a) and 9(a)) [2] and the numerical simulation (Figures 8(b) and 9(b)) [17], respectively, it is easy to reveal that the pressure nephogram distribution changing rule is similar. The maximum pressure peak appears in the position of the largest eccentricity. Positive and negative pressures distribute along the circumference. Comparing the pressure nephograms of Figures 8 and 9, respectively, it is easy to find that the pressure of the HGGJB is more than the PGJB. The reason is that the HGGJB have more stable bearing capability than the PGJB. Also the change rule of the crosssection pressure values (Figures $8(\mathrm{c})$ and $9(\mathrm{c})$ ) is similar on a whole, respectively, and all of them have a pressure peak in the biggest eccentric the same as the pressure nephogram. Besides, the trend of Figures 8(c) and 9(c) is like Figure 6(b) and Figure 7(b), respectively, in [15].

To sum up, for the PGJB and HGGJB on the whole both the pressure nephograms and the cross-section pressure 


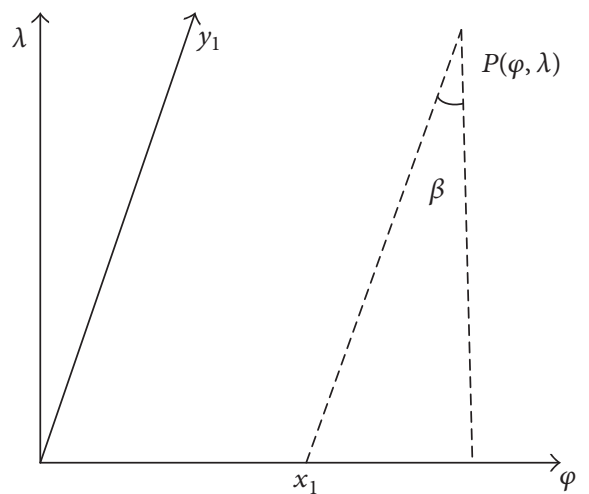

FIGURE 7: The oblique coordinate transformation.

curves calculated by the theoretical method and the numerical simulation are similar, respectively, illustrating correctness of our numerical simulations.

\section{Analysis of the Calculation Results}

In Sections 4.1 and 4.2, the parameters used for the HGGJB and PGJB are the parameters mentioned at the beginning of Section 3. The widths $B_{0}$ of the disk corresponding to the bearing capacities $0.5 \mathrm{~kg}, 1 \mathrm{~kg}, 2 \mathrm{~kg}$, and $2.5 \mathrm{~kg}$ are $7.5 \mathrm{~mm}$, $15 \mathrm{~mm}, 30 \mathrm{~mm}$, and $37.5 \mathrm{~mm}$, respectively. And the lengths $L_{1}$ of the bearing pedestal corresponding the length to width ratios of the bearing capacities $0.8,1.0,1.2$, and 1.6 are $40 \mathrm{~mm}$, $50 \mathrm{~mm}, 60 \mathrm{~mm}$, and $80 \mathrm{~mm}$, respectively. In Section 4.3 , influence of each parameter on dynamic characteristics of the HGGJB is analyzed, respectively, which is the only studied parameter that varied, whilst the other parameters keep the above-mentioned values.

4.1. Stability of the HGGJB Comparing with the PGJB. To highlight the advantage of the HGGJB in stability comparing with that of the PGJB, the rotor trajectory and the polar coordinates of the PGJB (Figure 10) and the HGGJB (Figure 11) at the rotating speed of $10000 \mathrm{r} / \mathrm{min}$ and under different bearing capacities, $M=1 \mathrm{~kg}, 2 \mathrm{~kg}$, and $2.5 \mathrm{~kg}$, are presented. The polar coordinate indicates that position of the rotor centre is at steady state. One finds that with the increase of the load bearing capacity the rotor eccentricity increases but the deviation angle decreases.

Basic operating parameters of the PGJB, including length $L$, radius $R$ and rotating speed $\omega$ of the gas bearing, clearance of the gas film $C_{0}$, pressure of the atmosphere $P_{a}$, viscosity of the air $\mu$, and the number of bearing, are shown in Table 3. Basic operating parameters of the HGGJB are already introduced at the beginning of Section 3; here we do not repeat them anymore and we also will not mention them anymore in the following parts. The initial condition is that the rotor begins to rotate from the center of the bearing under the standard atmospheric pressure.

From the trajectories shown in Figures 10(a) and 11(a), with the same rotating speed and the bearing capacity, we find that when the PGJB rotor operates in periodic whirling motion, the HGGJB rotor can settle in an equilibrium position all the time. So the HGGJB has higher stability. The reason is that the existence of herringbone grooves makes the sucked gas flow to the middle position of the agglomeration, increasing the stability of the flow. At the same time, the existence of the herringbone grooves inhibits the regular periodic whirling motion of the shaft center, making the HGGJB rotor more stable.

Figure 10(a) also shows that with the increase of the bearing capacity the rotating inertia increases, which makes the periodic whirling motion trajectory of the PGJB ovate from elliptic and the periodic whirling motion range becomes bigger and bigger.

The rotor trajectory of the HGGJB (Figure 11(a)) reveals obviously that the stability is becoming stronger with the increase of the bearing capacity and the time needed to reach the steady state is becoming shorter. On the other hand, the stability is becoming weaker with the decrease of the bearing capacity and the rotor trajectory tends to be unstable, which implies that the HGGJB is instable at the light load.

Further, we compare the polar coordinates of the HGGJB (Figure 11(b)) with that of the PGJB (Figure 10(b)), which reflect the change of the eccentricity and attitude angle of the rotor centre under different bearing capacities. Apparently the periodic whirling motion center of the PGJB attitude angle is relatively larger, which has more than 90 degrees under the light load. This indicates that the PGJB is in the unsteady periodic whirling motion state, while the attitude angle of the HGGJB (Figure 11(b)) is less than 90 degrees, which means that the HGGJB rotor is in a stable transient rotating motion.

To sum up, under the same rotating speed and bearing capacity, the HGGJB is more stable than the PGJB.

4.2. Bearing Capacity of the HGGJB Compared with the PGJB. To further highlight the advantage of the HGGJB, in this part, the maximum stable loading capacity of the HGGJB is compared with that of the PGJB. For this purpose, the rotor trajectory and polar coordinates of the HGGJB and PGJB under the same rotating speed, $10000 \mathrm{r} / \mathrm{min}$, are given in Figures 12(a) and 9(b), respectively. Here, basic parameters of the PGJB are still those shown in Table 3 and the bearing capacities for the PGJB and HGGJB are $0.5 \mathrm{~kg}$ and $2 \mathrm{~kg}$, respectively.

From Figure 12(a) we can see that the herringbone groove bearing moves quickly to achieve a stable equilibrium state after a few spiral laps from an origin position. For the plain bearing with poor flow regularity, it needs more spiral laps from the origin of coordinates to the equilibrium position. The bearing capacity for the PGJB is $0.5 \mathrm{~kg}$ in this case. When the bearing capacity is increased, the plain bearing will become unstable and the bearing periodic whirling motion phenomenon will appear.

From the polar coordinates of Figure 12(b), it is apparent that the stable center of the plain bearing is more near to the center of the bearing, implying that the plain bearing is more sensitive to the external disturbance excitation, while the herringbone groove bearing center is far away from the bearing center, meaning that the HGGJB can run more stably. 


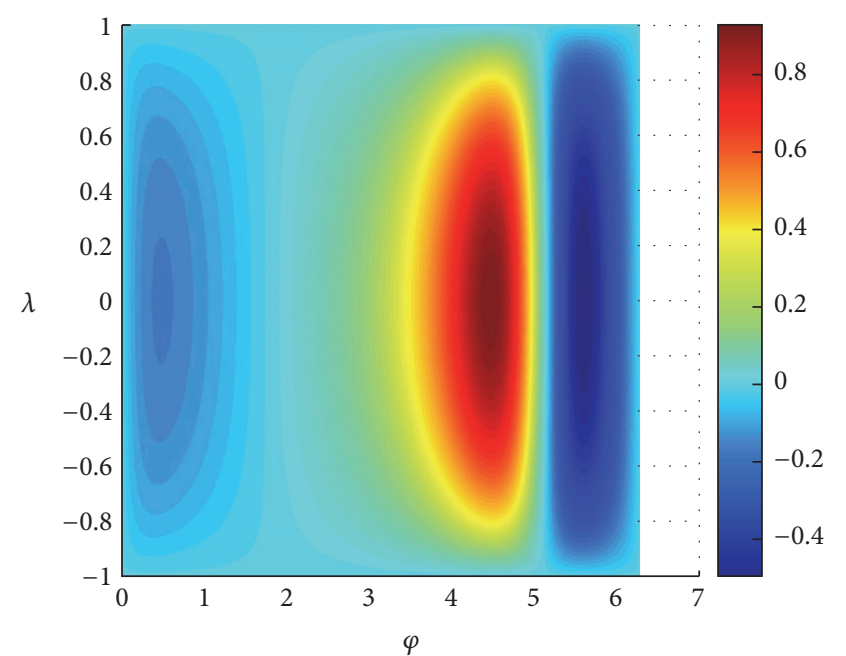

(a)

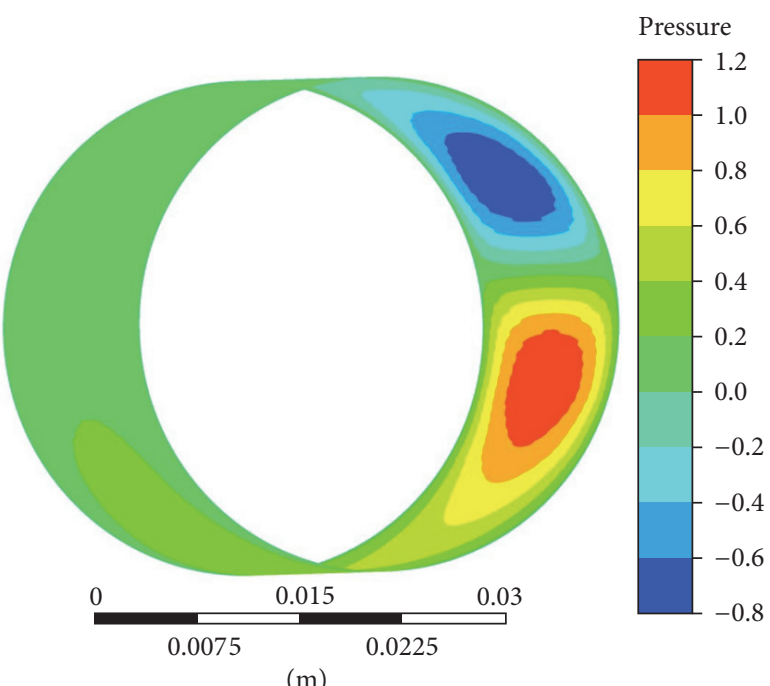

(b)

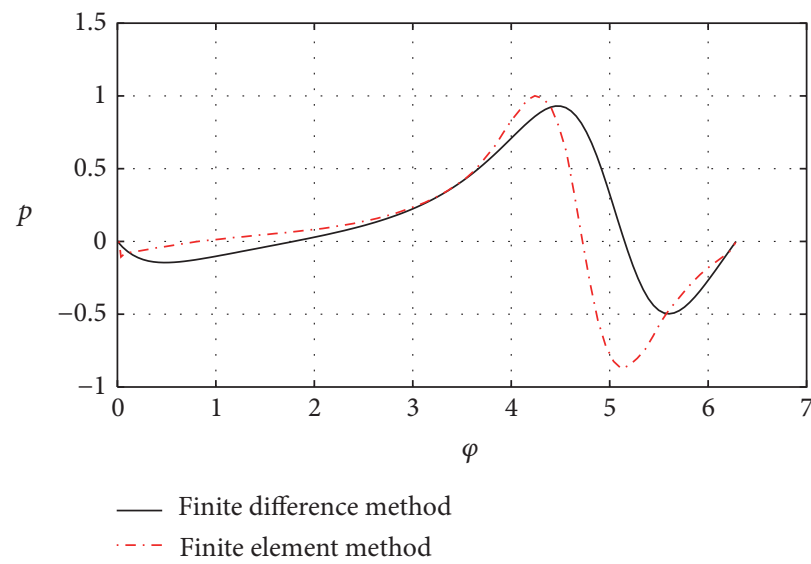

(c)

FIGURE 8: Nondimensional pressure nephogram of the PGJB by (a) the finite difference method and (b) the finite element method; (c) the corresponding circumferential pressure distribution curve of the cross-section of PGJB by the finite difference method and the finite element method.

In conclusion, both comparisons of the rotor trajectory and polar coordinates illustrate that under the same rotating speed the stable bearing capacity of the HGGJB is larger $(2 \mathrm{~kg} / 0.5 \mathrm{~kg}=4$ times) than that of the PGJB.

\subsection{Influences of the Structural and Operation Parameters on Dynamic Characteristics of the HGGJB}

4.3.1. The Spiral Angle. First, the effect of the spiral angle on dynamic characteristics of the HGGJB is analyzed. To this end, rotor trajectory and polar coordinates of the HGGJB under different spiral angle $\left(\beta=30^{\circ}, 45^{\circ}, 60^{\circ}, 90^{\circ}\right)$ are calculated, as shown in Figure 13.

From Figure 13(a), we can see that with the increase of the spiral angle, the transient fluctuation decreases first then increases and the final equilibrium position migrates downward along the $y$-axis. When the spiral angle reaches $90^{\circ}$ the periodic whirling motion appears. This indicates that the air collection of the constraint function is becoming stronger then weaker with the spiral angle increasing.

At the same time, the polar coordinates of Figure 13(b) show that with the increase of the spiral angle, the eccentricity decreases, and the attitude angle is reduced accordingly. It is consistent with the rotor trajectory. When the spiral angle is $45^{\circ}$, the equilibrium position is $(17.74,37.64)$ and the HGGJB acquires higher stability compared with the spiral angles $30^{\circ}$, $60^{\circ}$, and $90^{\circ}$ cases. When the spiral angle is $90^{\circ}$, the periodic whirling motion center elevates. Because the rotor operates in a small periodic whirling motion finally for both the $30^{\circ}$ and $60^{\circ}$ cases and this phenomenon is more obvious for the $90^{\circ}$ case, it indicates that the spiral angle should be neither too big nor too small.

4.3.2. The Groove Number. In this part, the effect of the groove number on dynamic characteristics of the HGGJB is studied. For this purpose, the rotor trajectory and polar 


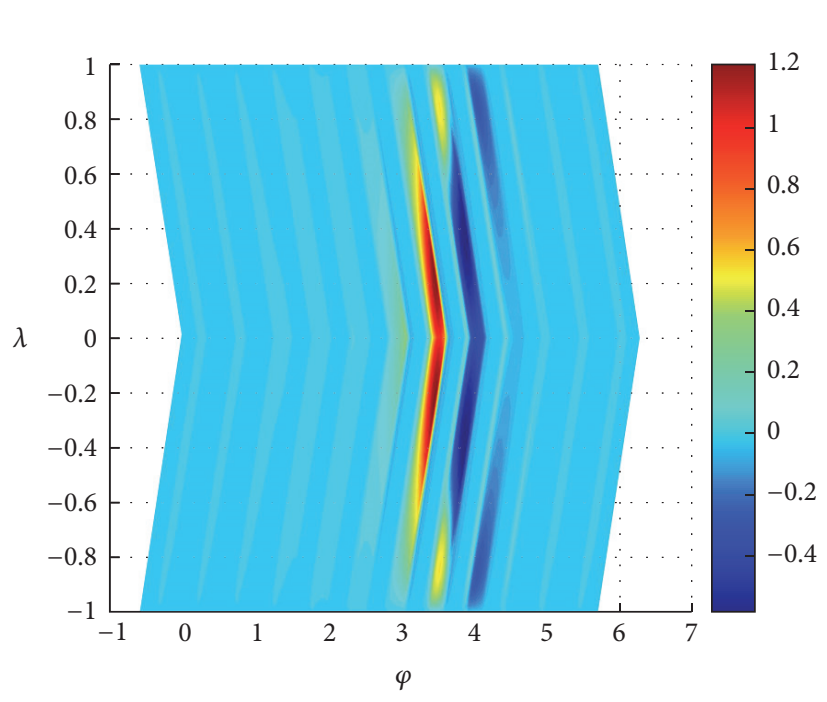

(a)

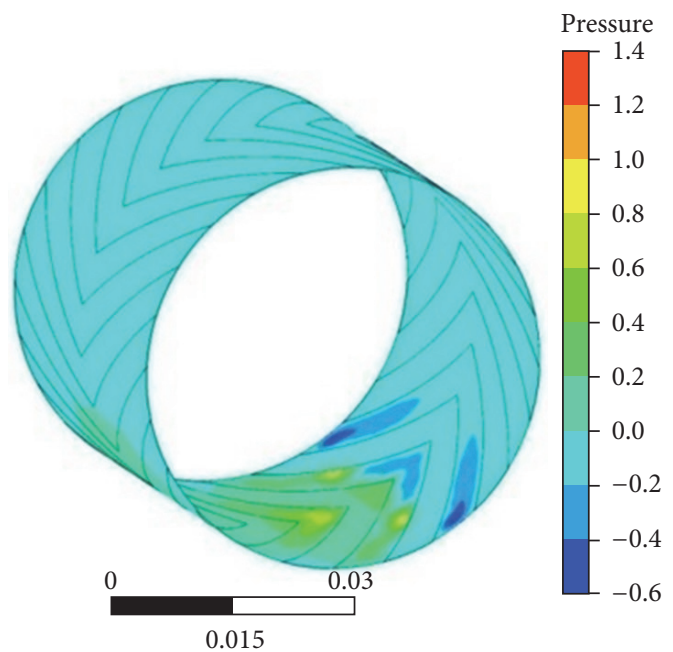

(m)

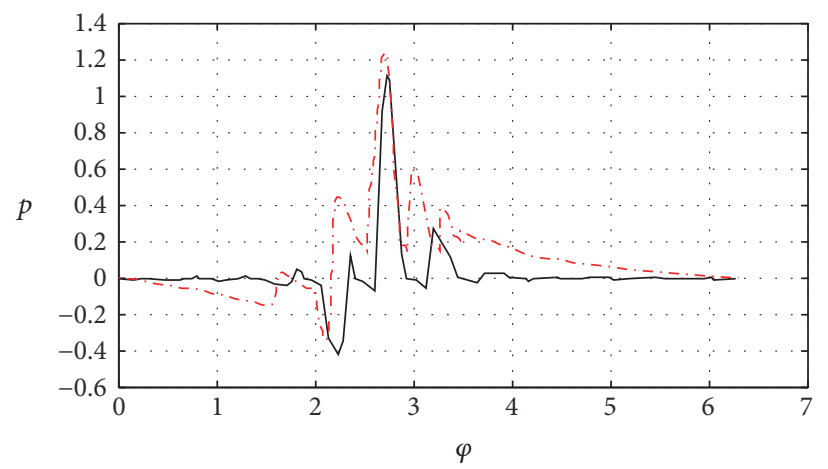

(b)

_ Finite difference method

. . . Finite element method

(c)

FIGURE 9: Nondimensional pressure nephogram of the HGGJB by (a) the finite difference method and (b) the finite element method; (c) the corresponding circumferential pressure distribution curve of the cross-section of HGGJB by the finite difference method and the finite element method.

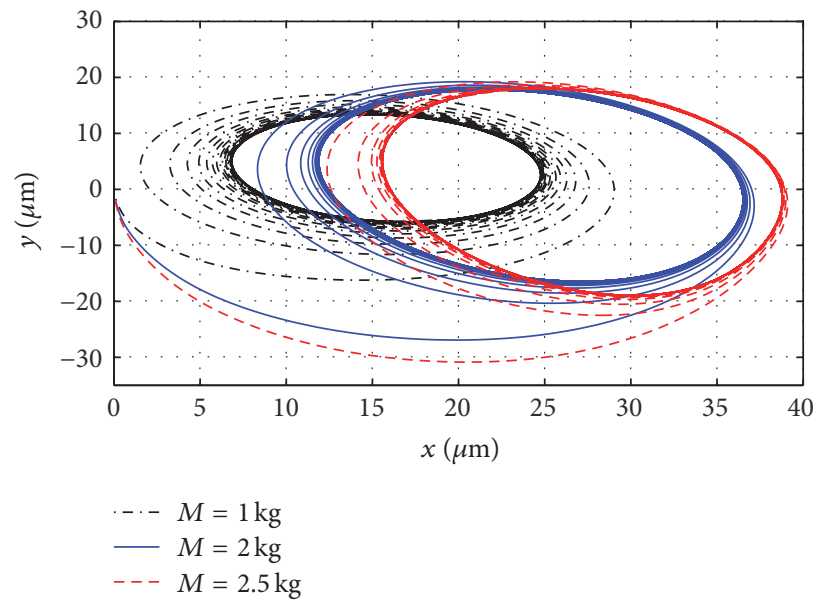

(a)

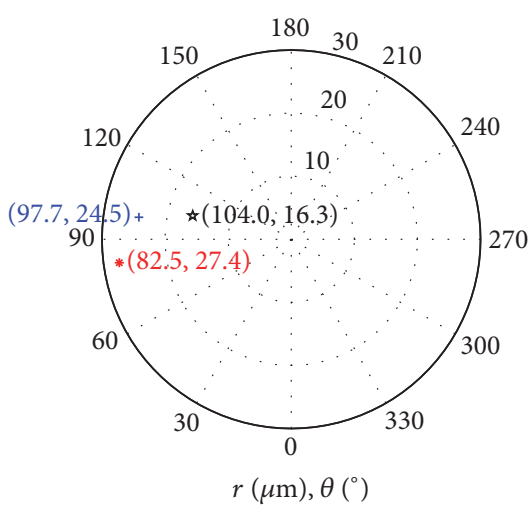

\ $M=1 \mathrm{~kg}$

$+M=2 \mathrm{~kg}$

* $M=2.5 \mathrm{~kg}$

(b)

FIGURE 10: (a) Rotor trajectory and (b) polar coordinates of the PGJB under different bearing capacities at the rotating speed of $10000 \mathrm{r} / \mathrm{min}$. 


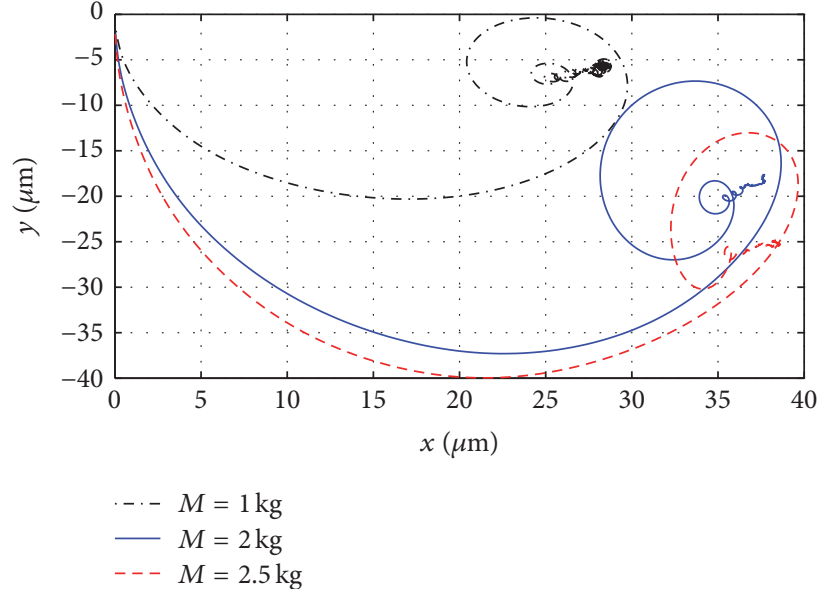

(a)

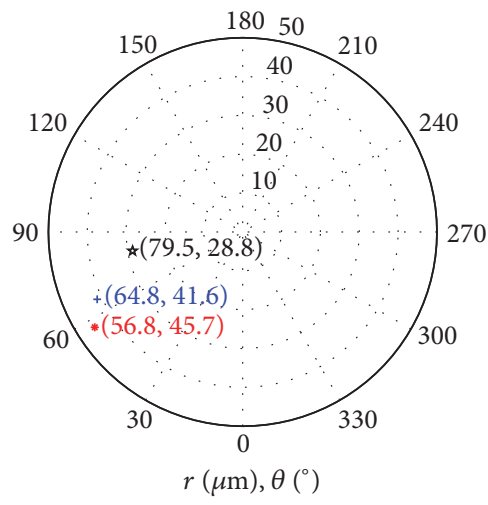

« $M=1 \mathrm{~kg}$

$+M=2 \mathrm{~kg}$

* $M=2.5 \mathrm{~kg}$

FIGURE 11: (a) Rotor trajectory and (b) polar coordinates of the HGGJB under different bearing capacities at the rotating speed of $10000 \mathrm{r} / \mathrm{min}$.

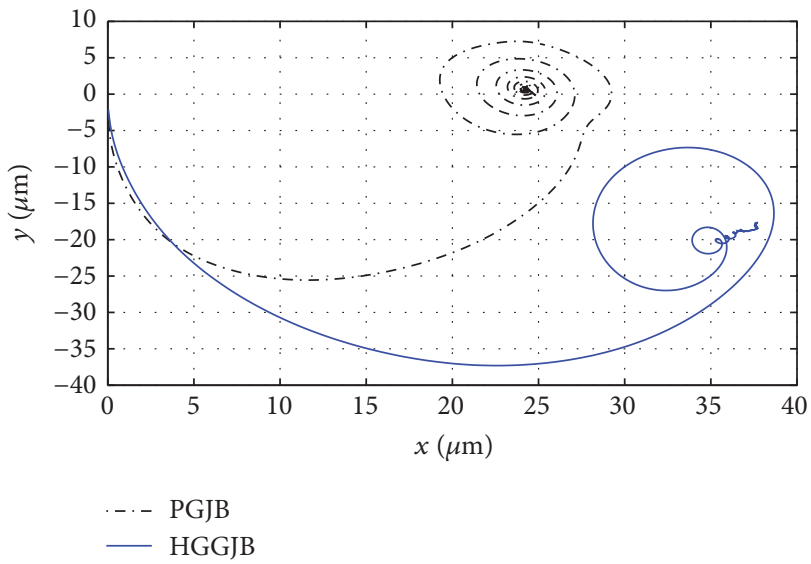

(a)

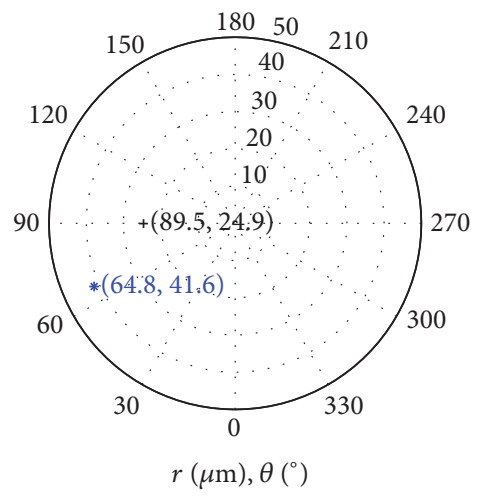

+ PGJB

* HGGJB

(b)

FIGURE 12: (a) Rotor trajectory and (b) polar coordinates of the HGGJB and PGJB at the rotating speed of $10000 \mathrm{r} / \mathrm{min}$.

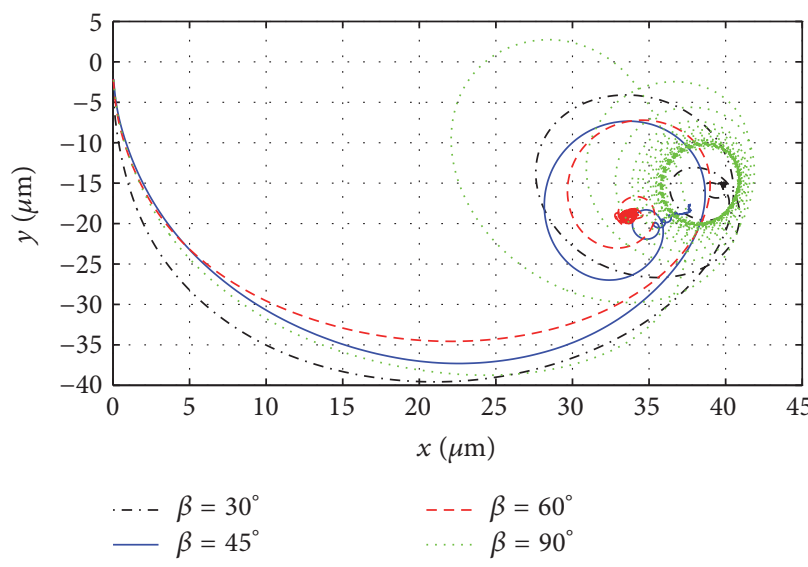

(a)

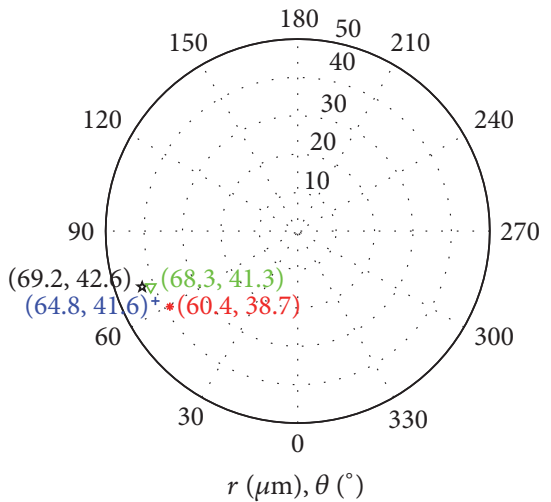

$$
\begin{array}{ll}
\star \beta=30^{\circ} & * \beta=60^{\circ} \\
+\beta=45^{\circ} & \nabla \beta=90^{\circ}
\end{array}
$$

(b)

FIGURE 13: (a) Rotor trajectory and (b) polar coordinates of the HGGJB under different spiral angles at the rotating speed of $10000 \mathrm{r} / \mathrm{min}$. 


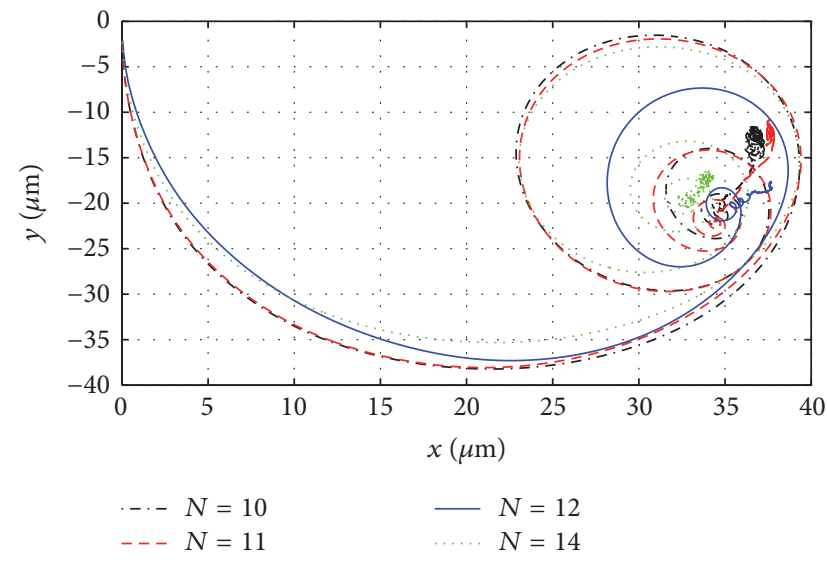

(a)

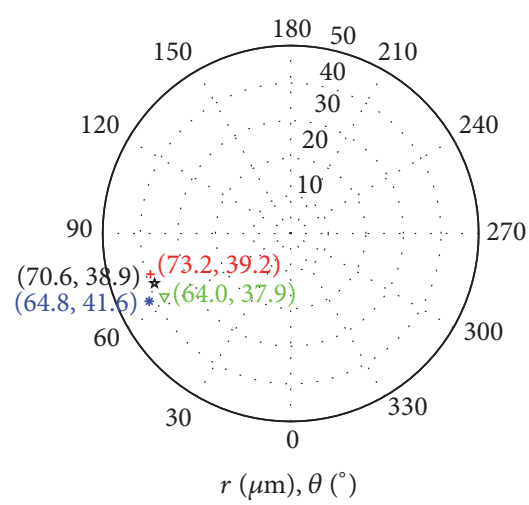

$\star N=10 \quad * N=12$

(b)

FIGURE 14: (a) Rotor trajectory and (b) polar coordinates of the HGGJB under different groove numbers at the rotating speed of $10000 \mathrm{r} / \mathrm{min}$.

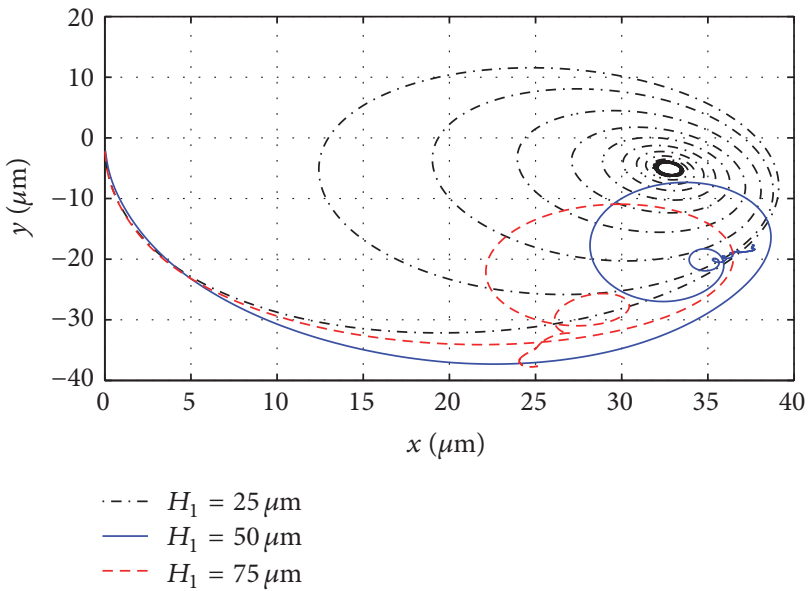

(a)

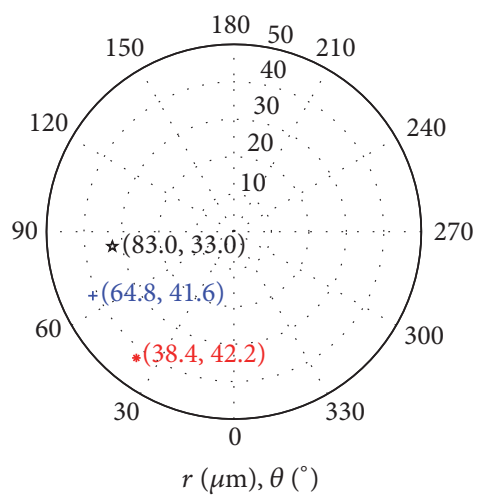

$\star H_{1}=25 \mu \mathrm{m}$

$+H_{1}=50 \mu \mathrm{m}$

* $H_{1}=75 \mu \mathrm{m}$

(b)

FIGURE 15: (a) Rotor trajectory and (b) polar coordinates of the HGGJB under different groove depth at the rotating speed of $10000 \mathrm{r} / \mathrm{min}$.

coordinates of the HGGJB under different groove numbers $N=10,11,12,14$ are depicted in Figure 14.

From Figure 14 it is easy to see that when the groove number is less than or larger than 12 , the transient rotating motion of the rotor is unstable in a region as it approaches the equilibrium position. In fact, the rotor cannot settle at a fix equilibrium point but whirls around a small area eventually if the groove number is less than or larger than 12.

With the groove number increasing from 10 to 12 , the fluid is becoming more regular and, when it is 14, the fluid becomes irregular. With the groove number increasing from 10 to 12 , the eccentricity and attitude angle increase and they decrease when the groove number is 14 .

4.3.3. The Groove Depth. To reveal the influence of the groove depth on dynamic characteristics of the HGGJB, rotor trajectory and polar coordinates of the HGGJB under different groove depths $H_{1}=25,50$, and $75 \mu \mathrm{m}$ are depicted in Figure 15. One finds that when the groove depth is $25 \mu \mathrm{m}$, the rotor settles at a periodic whirling motion with the minimum eccentricity and the largest attitude angle. When the groove depth is $75 \mu \mathrm{m}$, the transient rotating motion is unstable, whereas it approaches to transient rotating motion at the fixed equilibrium position finally with the large eccentricity and low attitude angle. When the groove depth is $50 \mu \mathrm{m}$, the eccentricity and attitude angle are between the above two kinds of states.

4.3.4. The Pressure Relief Hole Diameter. To analyze the influence of the pressure relief hole diameter [18] on dynamic characteristics of the HGGJB, rotor trajectory and polar coordinates of the HGGJB under different pressure relief hole diameter $D_{2}=0,2,3 \mathrm{~mm}$ are given in Figure 16. Obviously, the rotational attitude angle and the eccentricity stability gradually increase with the increase of the pressure relief hole diameter. Specially, when the pressure relief hole diameter is $0 \mathrm{~mm}$, the bearing outlets become the air inlet and outlet at the same time, which leads to the bearing gases colliding each 


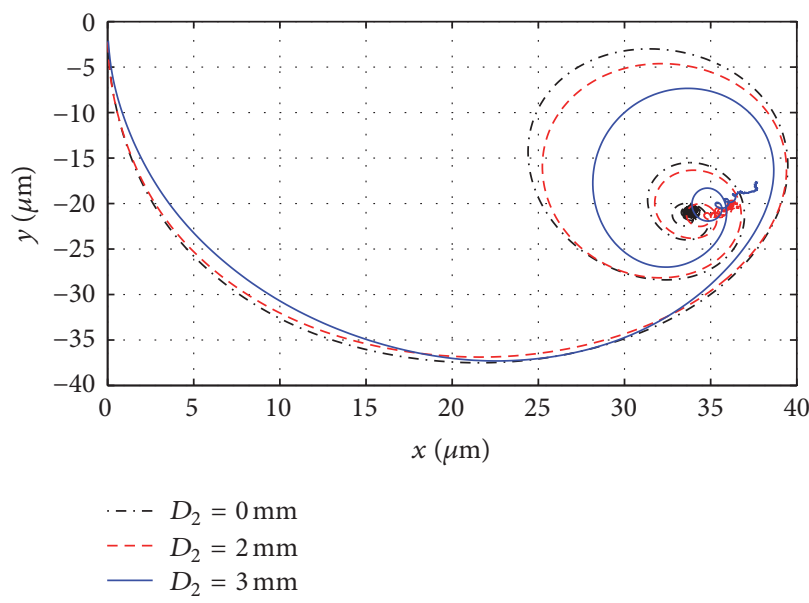

(a)

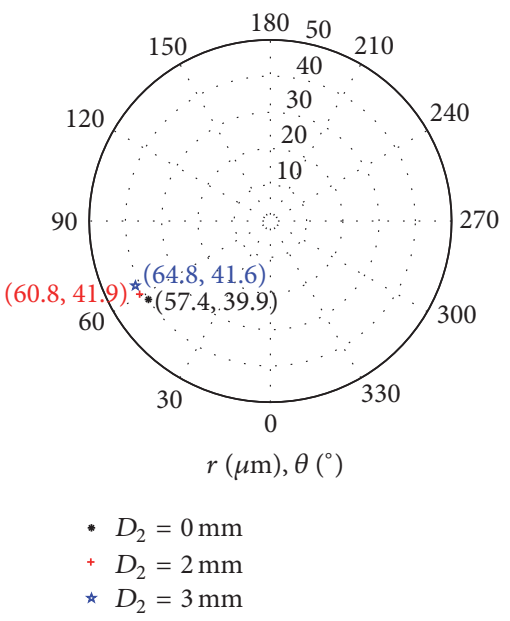

(b)

FIGURE 16: (a) Rotor trajectory and (b) polar coordinates of the HGGJB under different pressure relief hole diameter at the rotating speed of $10000 \mathrm{r} / \mathrm{min}$.

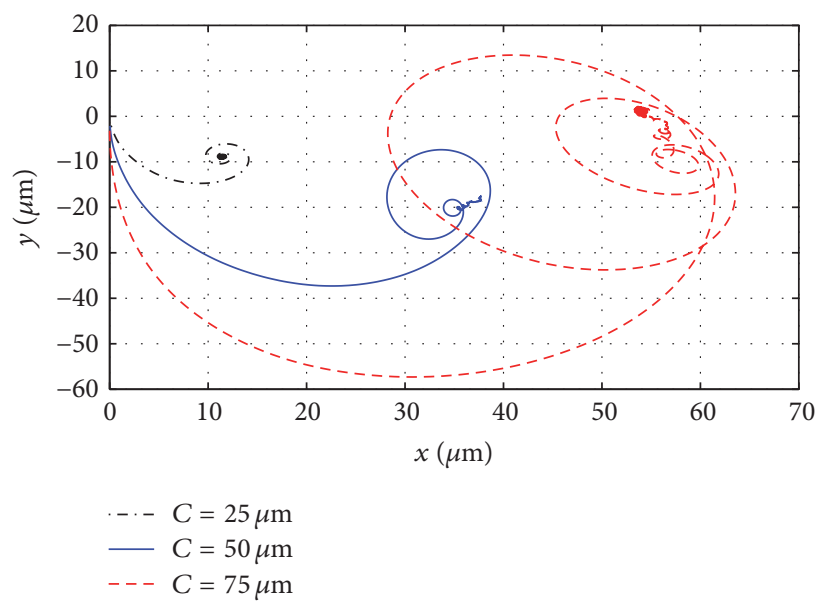

(a)

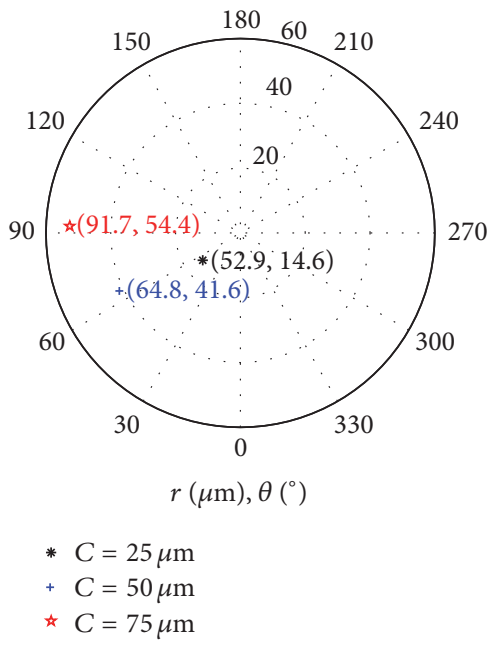

(b)

FIGURE 17: (a) Rotor trajectory and (b) polar coordinates of the HGGJB under different bearing radial clearance at the rotating speed of $10000 \mathrm{r} / \mathrm{min}$.

other in the process of the flow, thus producing internal selfexcited vibration and affecting the movement of the rotor. With the pressure relief hole diameter increasing from $0 \mathrm{~mm}$ to $2 \mathrm{~mm}$, the eccentricity and the attitude angle increase obviously; correspondingly the stability increases. With the pressure relief hole diameter increasing from $2 \mathrm{~mm}$ to $3 \mathrm{~mm}$, the eccentricity changes a little but the attitude angle increases significantly, still meaning that the stability of the rotating rotor is increased. Apparently, the bigger the pressure relief hole diameter, the better the performance of the HGGJB. This indicates that the significance of the pressure relief hole diameter on the performance of HGGJB is to regulate the gas suction and pump out and restrain the motion of the gas in the middle of the HGGJB and thus make the rotor operate more stably.
4.3.5. The Bearing Radial Clearance. Influence of the bearing radial clearance $C$ on dynamic characteristics of the HGGJB is revealed by Figure 17 for $C=25,50$, and $75 \mu \mathrm{m}$. One finds that when the bearing radial clearance is $25 \mu \mathrm{m}$, the eccentricity and attitude angle are relatively small, and the transient fluctuation is also slight. When the bearing radial clearance increases to $50 \mu \mathrm{m}$, the rotor is transient rotating motion in the stable position, whereas the attitude angle and eccentricity increase accordingly. As the film thickness increases to $75 \mu \mathrm{m}$, the rotor motion becomes unstable in the last stage. The attitude angle and eccentricity increase continuously and the former reaches more than 90 degrees eventually. So for the examples studied above, $50 \mu \mathrm{m}$ is the optimized bearing radial clearance. The result indicates that the bearing radial clearance should be the same as the groove depth. 


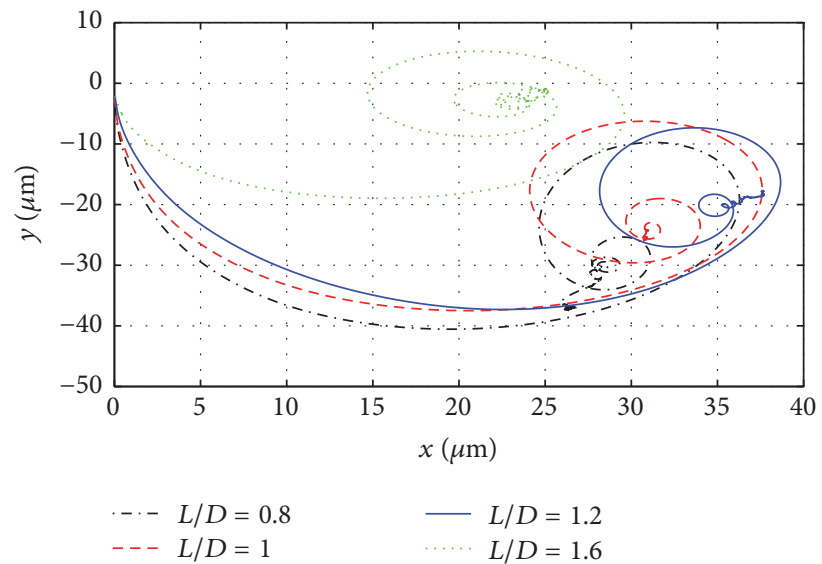

(a)

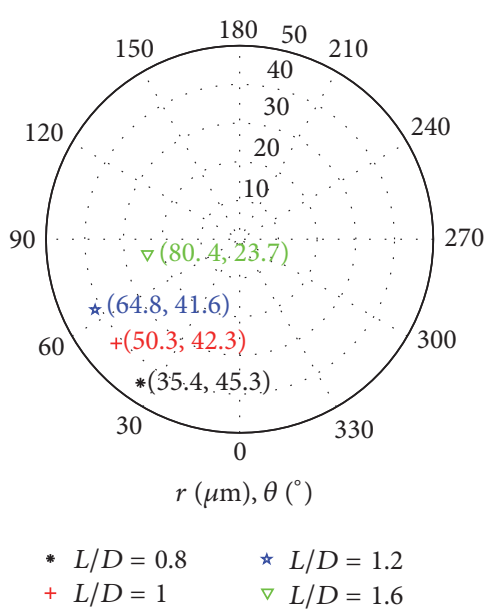

(b)

FIGURE 18: (a) Rotor trajectory and (b) polar coordinates of the HGGJB under different length to diameter ratio at the rotating speed of $10000 \mathrm{r} / \mathrm{min}$.

4.3.6. The Length to Diameter Ratio. Influence of the length to diameter ratio $L / D$ on dynamic characteristics of the HGGJB is revealed by Figure 18 for $L / D=0.8,1,1.2,1.6$. It is obvious that the length to diameter ratio has great influence on dynamic characteristics of the HGGJB. With the increase of the length to diameter ratio, the stability of the rotating rotor is increased. Whilst the attitude angle increases, the eccentricity has experienced a process of decreasing. The eccentricity and the attitude angle reflect the bearing capacity. The bigger the attitude angle and the smaller the eccentricity, the more improvement of the rotating change space of the rotor. So the maximum bearing capacity will increase with the attitude angle increasing and the smaller the eccentricity decreasing. Therefore, increasing the length to diameter ratio can effectively improve the bearing capacity.

\section{Conclusions}

In this paper, dynamic characteristic of the HGGJB under fluid-structure interactions are systematically studied using CFD and FEM method. Some conclusions are as followings:

(1) Under the same rotating speed and bearing capacity, the HGGJB have higher stability ability than the PGJB.

(2) The spiral angle, the film thickness, the groove number and the groove depth should be neither too big nor too small. The bigger the pressure relief hole diameter and the length to diameter ratio, the more stable the HGGJB.

(3) Due to the constraints of the herringbone grooves, the air flows from the herringbone groove to the middle part of the bearing which makes the air distribution more regular and thus increases the stability of the rotor system. This is the fundamental reason why the HGGJB are superior.

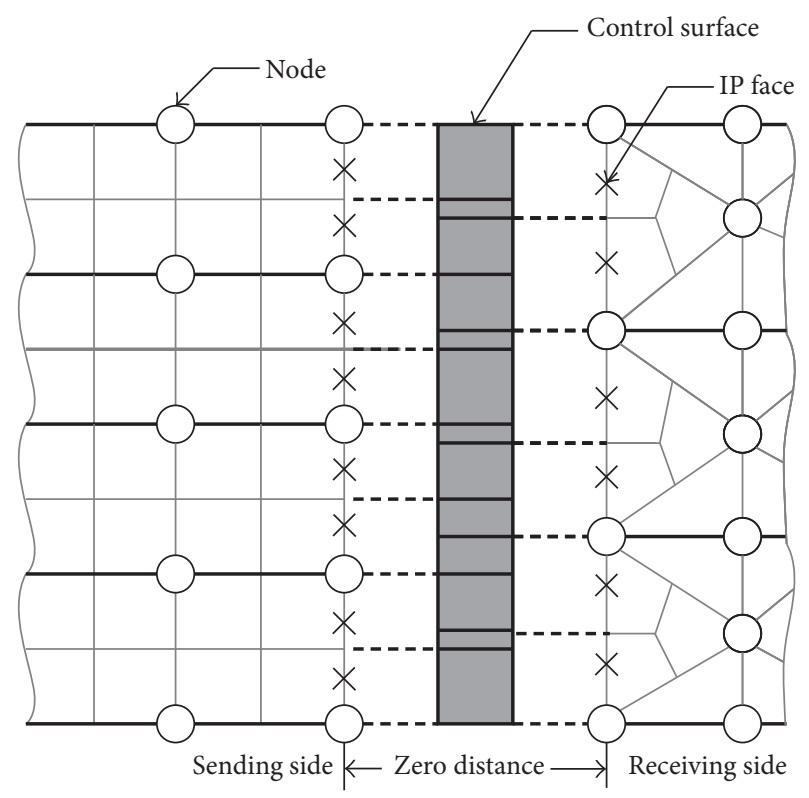

FIGURE 19: Schematic diagram of the nodes coupling in fluidstructure interactions.

\section{Appendix}

\section{A. Basic Principle of the Fluid Structure Interactions}

To simulate the dynamic characteristics of the HGGJB and PGJB through Ansys, the fluid structure interactions are involved. It means that in the calculation the fluid and the structure need to transfer data to each other. The basic principle of the fluid structure interactions, that is, the data transfer process of the nodes coupling, is depicted in Figure 19. In order to transfer the data between the nonsimilar grids, the 


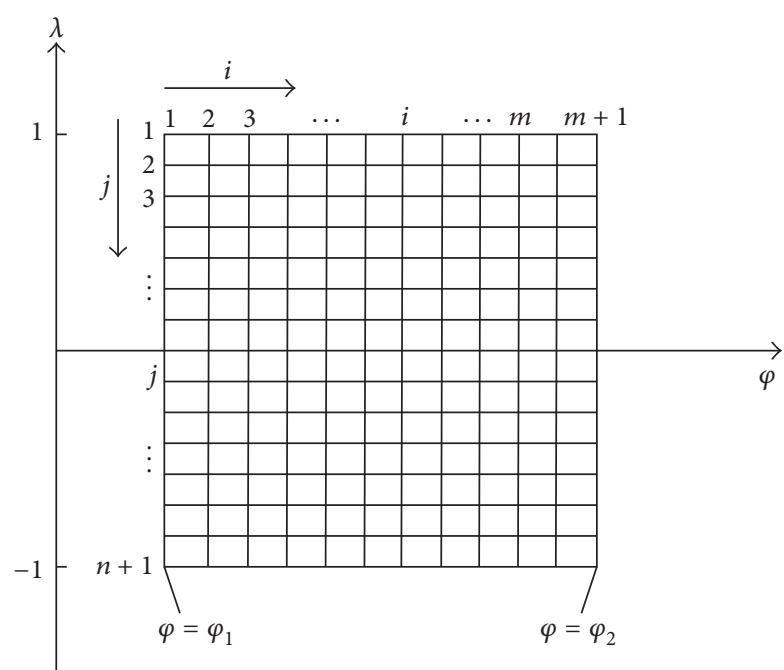

FIgURE 20: Schematic diagram of the expanded grids of the bearing.

nodes on each grid must be mapped to the corresponding grid cell. To transfer displacements, the nodes of the fluid coupling surface must be mapped to the solid coupling cell. To transfer the stress, the nodes of the solid coupling cell must be mapped to the fluid coupling surface. That is to say, for one time of node coupling, two times of data transfer must be implemented.

\section{B. Basic Principle of the Finite Difference Method}

To calculate pressure distribution of the gas bearing by the finite difference method, the gas film needs to be divided into many grids. For a cylindrical bearing, the outer surface is expanded into a rectangular face along the generatrix and then evenly meshed in $\varphi$ and $\lambda$ directions, as shown in Figure 20.

The mesh nodes are numbered orderly according to the row and column they belong to. The numbers are designated as $i(i=1, \ldots, m+1)$ and $j(j=1, \ldots, n+1)$, and then the space steps are $\Delta \varphi=\left(\varphi_{2}-\varphi_{1}\right) / m$ and $\Delta \lambda=L / n$, respectively. The pressure at node $(i, j)$ is $P_{i j}$.

For herringbone bearing structure, after expansion, its surface is segmented by grooves. Parallel quadrilateral mesh along the groove is then used in the computation as shown in Figure 21. Areas $a$ and $b$ contain the nodes only in and out of the groove, respectively, whereas areas $c$ and $d$ contain both of them.

\section{Nomenclature}

$D_{0}$ : Diameter of the disk (mm)

$B_{0}$ : Width of the disk $(\mathrm{mm})$

$L_{0}$ : Axial length $(\mathrm{mm})$

$D$ : Axial diameter ( $\mathrm{mm})$

$B_{1}$ : Thickness of the bearing pedestal $(\mathrm{mm})$

$D_{1}$ : Diameter of the bearing pedestal $(\mathrm{mm})$

$L_{1}$ : Length of the bearing pedestal $(\mathrm{mm})$

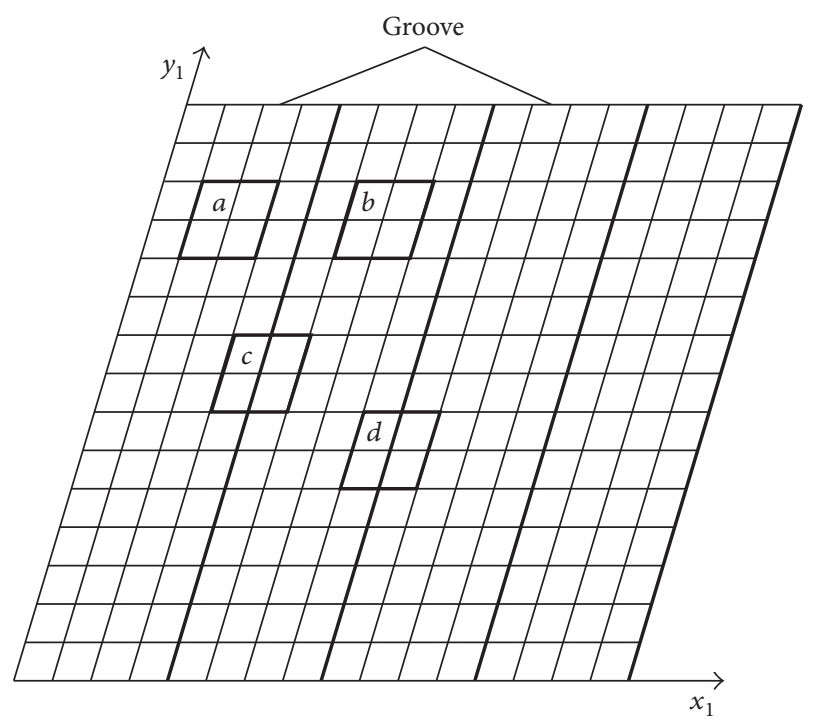

FIGURE 21: Schematic diagram of the grids distribution under oblique coordinate system.

$L: \quad$ Length of the gas bearing $(\mathrm{mm})$

$R: \quad$ Radius of gas bearing $(\mathrm{mm})$

$\omega: \quad$ Rotating speed of gas bearing $(\mathrm{rad} / \mathrm{s})$

$C_{0}$ : Clearance of gas film (mm)

$P_{a}: \quad$ Atmosphere

$\mu$ : $\quad$ Viscosity of air (Pa.s)

$\beta$ : $\quad$ Spiral angle

$N$ : $\quad$ Groove number

$H_{1}: \quad$ Groove depth (mm)

$D_{2}$ : Pressure relief hole $(\mathrm{mm})$

$C: \quad$ Bearing radial clearance $(\mathrm{mm})$

$L / D$ : Length to diameter

$\varepsilon: \quad$ Eccentricity ratio

$e: \quad$ Eccentric distance $(\mathrm{mm})$

$\psi: \quad$ The ratio of the clearance

$\varphi$ : $\quad$ Angle

$x_{1}, y_{1}$ : Oblique coordinate

$z: \quad$ Cartesian coordinate

$P: \quad$ Pressure $(\mathrm{Pa})$

$h$ : Circumferential clearance $(\mathrm{mm})$

$\lambda$ : Dimensionless axial distance

$H$ : Dimensionless circumferential clearance.

\section{Competing Interests}

The authors declare that they have no competing interests.

\section{Acknowledgments}

The research is supported by the National Natural Science of China under Grants nos. 51575378 and 11502162 and the NSF of Tianjin under Grants nos. 13JCZDJC34900 and 15JCQNJC05100. Yongtao Sun is also supported by the Seed Foundation of Tianjin University (no. 1405), the fund from State Key Laboratory for Strength and Vibration of Mechanical Structures (Xian Jiaotong University, no. SV2015-KF-02), 
the fund from State Key Laboratory of Structural Analysis for Industrial Equipment (Dalian University of Technology, no. GZ1408), and the fund from State Key Laboratory of Mechanical System and Vibration (Shanghai Jiaotong University, no. MSV201611).

\section{References}

[1] N. Zirkelback and L. San Andrés, "Finite element analysis of herringbone groove journal bearings: A Parametric Study," Journal of Tribology, vol. 120, no. 2, pp. 234-240, 1998.

[2] G. H. Jang and D. I. Chang, "Analysis of a hydrodynamic herringbone grooved journal bearing considering cavitation," Journal of Tribology, vol. 122, no. 1, pp. 103-109, 2000.

[3] G. H. Jang and J. W. Yoon, "Nonlinear dynamic analysis of a hydrodynamic journal bearing considering the effect of a rotating or stationary herringbone groove," Journal of Tribology, vol. 124, no. 2, pp. 297-304, 2002.

[4] T. V. V. L. N. Rao and J. T. Sawicki, "Stability characteristics of herringbone grooved journal bearings incorporating cavitation effects," Journal of Tribology, vol. 126, no. 2, pp. 281-287, 2004.

[5] A. M. Gad, M. M. Nemat-Alla, A. A. Khalil, and A. M. Nasr, "On the optimum groove geometry for herringbone grooved journal bearings," Journal of Tribology, vol. 128, no. 3, pp. 585-593, 2006.

[6] C.-C. Wang, "Bifurcation analysis of an aerodynamic journal bearing system considering the effect of stationary herringbone grooves," Chaos, Solitons and Fractals, vol. 33, no. 5, pp. 15321545, 2007.

[7] C.-C. Wang, H.-T. Yau, M.-J. Jang, and Y.-L. Yeh, “Theoretical analysis of the non-linear behavior of a flexible rotor supported by herringbone grooved gas journal bearings," Tribology International, vol. 40, no. 3, pp. 533-541, 2007.

[8] C.-C. Wang, "Theoretical and nonlinear behavior analysis of a flexible rotor supported by a relative short herringbone-grooved gas journal-bearing system," Physica D, vol. 237, no. 18, pp. 2282-2295, 2008.

[9] C.-C. Wang, "Application of a hybrid method to the nonlinear dynamic analysis of a flexible rotor supported by a spherical gaslubricated bearing system," Nonlinear Analysis. Theory, Methods \& Applications, vol. 70, no. 5, pp. 2035-2053, 2009.

[10] T. Hirayama, N. Yamaguchi, S. Sakai, N. Hishida, T. Matsuoka, and H. Yabe, "Optimization of groove dimensions in herringbone-grooved journal bearings for improved repeatable runout characteristics," Tribology International, vol. 42, no. 5, pp. 675-681, 2009.

[11] M. A. Hassini and M. Arghir, "A simplified nonlinear transient analysis method for gas bearings," Journal of Tribology, vol. 134, no. 1, Article ID 011704, 2012.

[12] M. A. Hassini and M. Arghir, "A new approach for the stability analysis of rotors supported by gas bearings," in Proceedings of the ASME Turbo Expo 2013: Turbine Technical Conference and Exposition (GT '13), San Antonio, Texas, USA, June 2013.

[13] M. A. Hassini and M. Arghir, "A simplified and consistent nonlinear transient analysis method for gas bearing: extension to flexible rotors," Journal of Engineering for Gas Turbines and Power, vol. 137, no. 9, Article ID 092502, 2015.

[14] J. Schiffmann and D. Favrat, "The effect of real gas on the properties of herringbone grooved journal bearings," Tribology International, vol. 43, no. 9, pp. 1602-1614, 2010.
[15] C.-Y. Chen, R.-H. Yen, and C.-C. Chang, "Spectral element analysis of herringbone-grooved journal bearings with grooveridge discontinuity," International Journal for Numerical Methods in Fluids, vol. 66, no. 9, pp. 1116-1131, 2011.

[16] J. Schiffmann, "Enhanced groove geometry for herringbone grooved journal bearings," Journal of Engineering for Gas Turbines and Power, vol. 135, no. 10, Article ID 102501, 2013.

[17] K. M. Panday, P. L. Choudhury, and N. P. Kumar, "Numerical unsteady analysis of thin film lubricated journal bearing," International Journal of Engineering and Technology, vol. 4, no. 2, pp. 185-191, 2012.

[18] Y.-F. Wang, Gas Lubrication Theory and the Design of Gas Bearing, China Machine Press, 1999. 


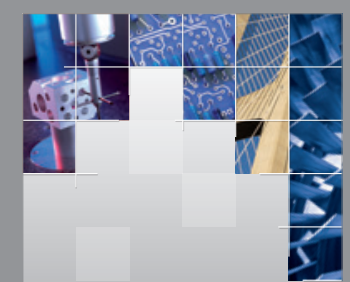

\section{Enfincering}
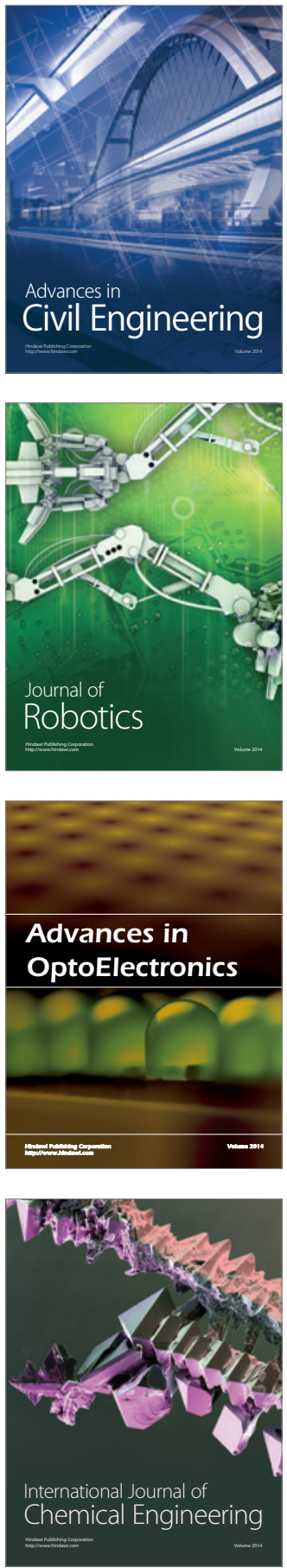

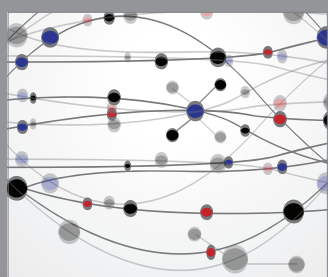

The Scientific World Journal

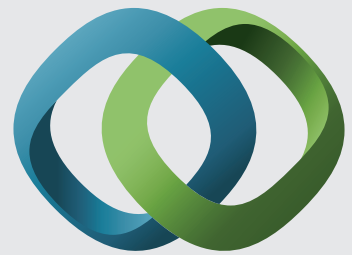

\section{Hindawi}

Submit your manuscripts at

http://www.hindawi.com
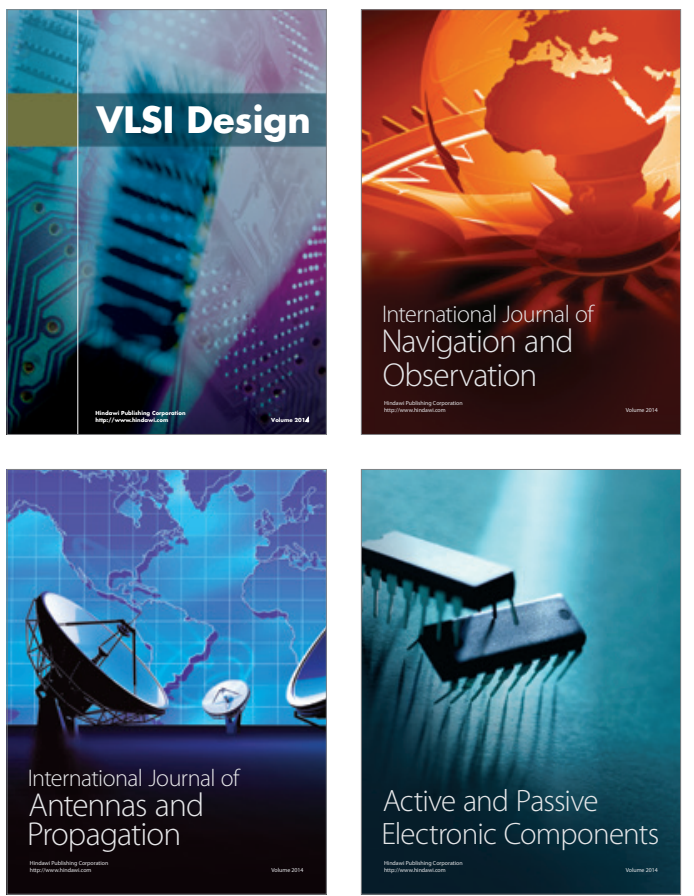
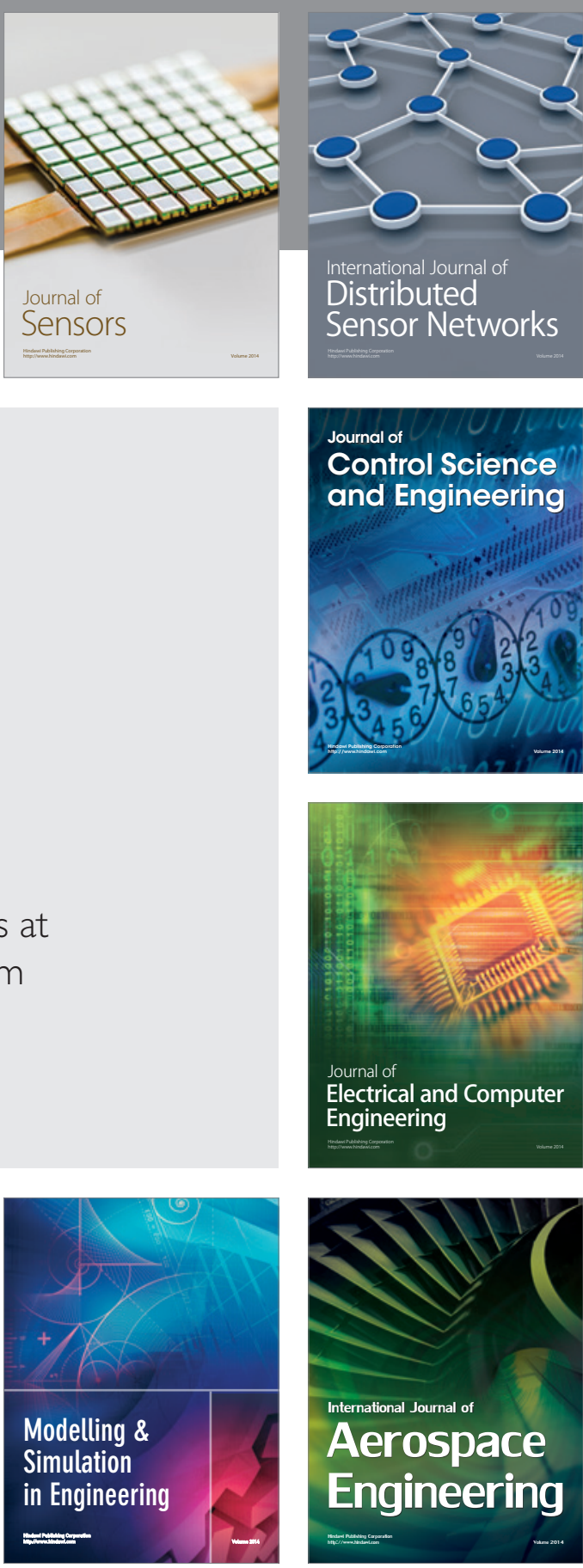

International Journal of

Distributed

Sensor Networks

Journal of

Control Science

and Engineering
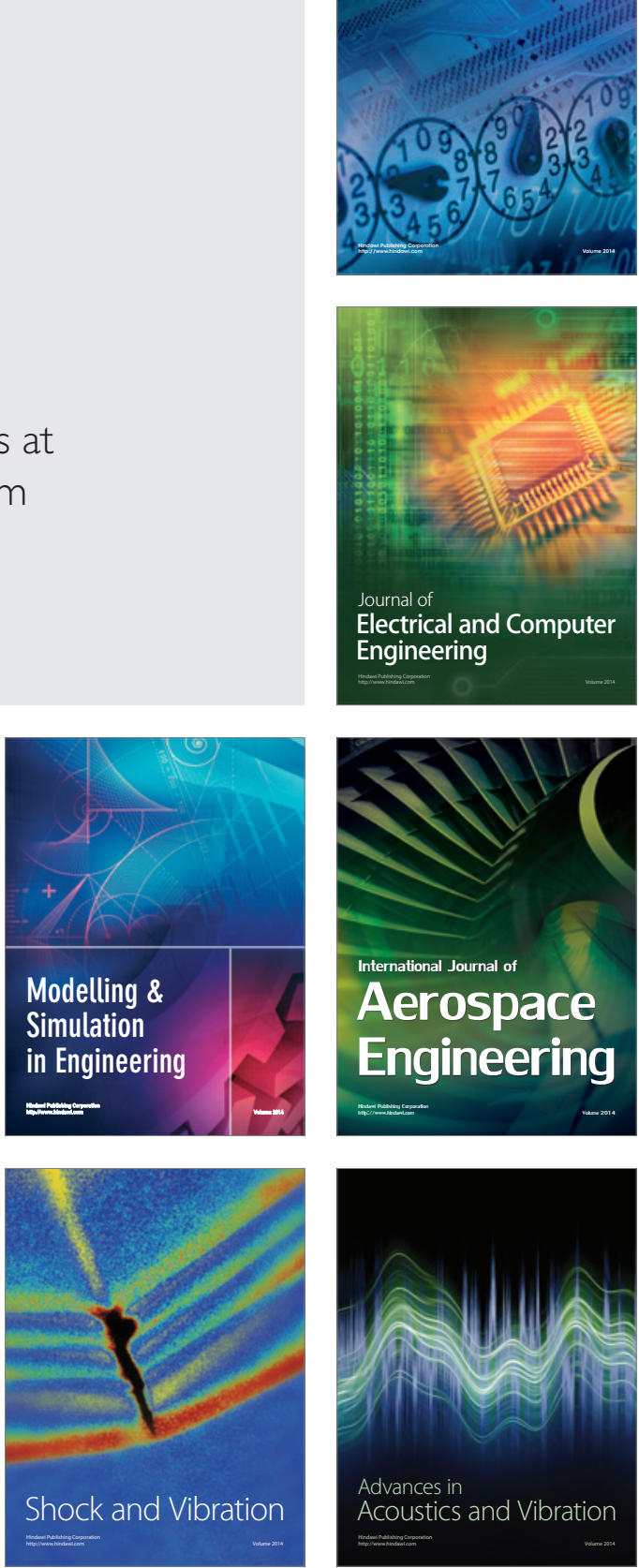